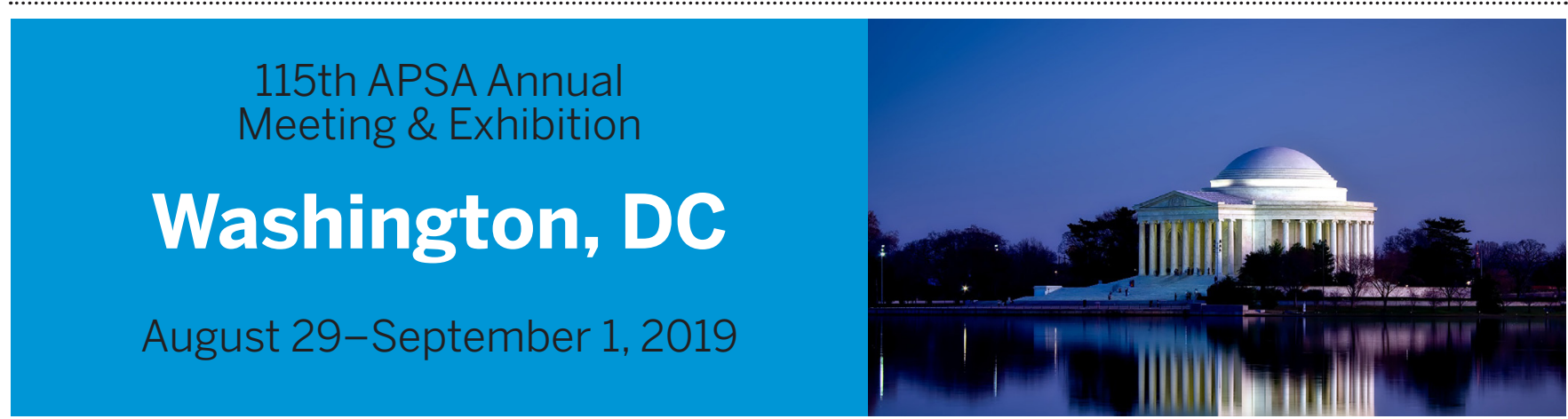

\section{Populism and Privilege}

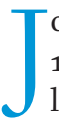
oin APSA in Washington, DC for the 115th Annual Meeting to address the latest scholarship in political science while exploring the theme, "Populism and Privilege." APSA and the 2019 Program Chairs Amel Ahmed, University of Massachusetts, Amherst, and Christopher Sebastian Parker, University of Washington, look forward to your participation in panels and sessions prepared by APSA's 57 divisions and numerous related groups at the 2019 APSA Annual Meeting.

The call for proposals for divisions, related groups, TLC at APSA, and preconference short courses will close at 11:59 p.m. PST on January 15, 2019. Learn more about the specific participant rules, limitations, and exemptions, as well as submission options on the 2019 APSA Annual Meeting website: www.connect.apsanet.org/apsa2019/.

Also, visit the website for transportation and housing tips and group rates. Be sure to register online before July 9, 2019 for early bird rates and check out transportation and housing rates early to secure your spot for the meeting.

\section{THEME STATEMENT}

The 2019 themse statement, written by program chairs Amel Ahmed and Christopher Sebastian Parker:

No recent political development has been more striking than the rise to power of self-identified populist movements around the globe, whose main unifying trait is their claim to champion "the people" against entrenched selfish "elites." These movements display differences that have sparked debates over which, if any, should be called "populist"; how they compare with past "populisms"; and what "populism" is. The current partisans, often labeled populist, have more often been on the right than the left, including anti-immigrant, anti-globalization, ardently nationalist parties such as Fidesz in Hungary; the Law and Justice Party in Poland; and the Trump Republicans in the United States. Until recently, however, left-wing populist movements were ascendant in Latin America. In fact, they remain important there and in other regions, something suggested by support for Bernie Sanders in the 2016 American primaries. Some positions increasingly labeled as populist, such as the Chinese nationalism of Xi Jinping, represent forms of state capitalism that are harder to identify on either the left or right. Indeed, modern "populist" movements have a wide variety of economic agendas, even as most push against the leading institutions of the global economic order, such as the IMF, the World Bank, and multilateral trade agreements. Some, such as in Erdogan's Turkey and Modi's India, are stridently religious; others, like the anti-immigrant populisms in Europe and the United States, often feature racial and cultural themes.

These surging populist movements have transformed politics within nations and across nations, so they have become central to research in every political science subfield. Americanists seek to explain the rise of Trump; comparativists, a range of other populist movements in many lands; international relations scholars gauge national populists' impact on international security and economic institutions, such as NATO and NAFTA; political theorists seek to grasp the implications of these populisms for democratic theory, for the very concept of "the people," as well as theories of identity concerned with race, religion, gender, nation, and class. Public law scholars focus on their implications for constitutionalism and the rule of law. Specialists in political economy, public policy, and public administration all find their stan- dard models challenged by the actions of many new populist governments.

This scholarship raises vital questions about whether some or all of these self-labeled populist movements represent understandable, indeed legitimate responses to entrenched, self-serving privileges and perspectives of global and national elites-economic, social, and cultural-or whether they instead represent efforts to preserve privileges of established groups against economic, demographic, and cultural transformations. Are they about race? Are they about class, or fears of loss of economic status? Are they about religion? Are they about national identity? Are they fundamentally anti-democratic, or expressions of democracy? If they are combinations of motives of various sorts, what are those varieties, and why are they present?

Should most of the recent populist movements be seen as versions of historical forms of populism, or are we encountering significantly new phenomena? Is it useful to analyze these movements as forms of "populism" at all? What might they achieve? What are their effects on political institutions, public policies, and/or political or public culture(s)? Current research provides no settled answers. For the 2019 annual meeting, scholars throughout the discipline are invited to explore how political scientists should explain and assess the new self-proclaimed populist movements, their relationships to various systems of privilege, their historical antecedents, and their probable trajectories-as well as what kinds of political responses to them might serve as a feasible challenge, and what kinds might be normatively desirable. 